\title{
Synthesis and Structural Characterization of U-Zr-Nb Alloys
}

\author{
Ailton da Silva Ferreira ${ }^{a *}$, Fábio Rogério Longen ${ }^{b}$, Ricardo Augusto Mascarello Gotardo ${ }^{c}$,
}

Flávio Francisco Ivashita ${ }^{d}$, Reginaldo Barco ${ }^{d}$, Andrea Paesano Júnior ${ }^{d}$

${ }^{a}$ Instituto Federal Catarinense, Abelardo Luz, SC, Brazil

${ }^{b}$ Universidade Tecnológica Federal do Paraná, Medianeira, PR, Brazil

'Universidade Tecnológica Federal do Paraná, Cornélio Procópio, PR, Brazil

${ }^{d}$ Departamento de Física, Universidade Estadual de Maringá, Maringá, PR, Brazil

Received: April 27, 2017; Revised: July 31, 2017; Accepted: September 17, 2017

\begin{abstract}
$\mathrm{U}-x \mathrm{Zr}-y \mathrm{Nb}$ alloys with values of $x$ varying from $32 \%$ to $50 \%$ (wt.\%Zr) and $y$ varying from $6 \%$ to $10 \%(\mathrm{wt} . \% \mathrm{Nb})$ were produced by the arc melting technique. The effect of the addiction of zirconium and niobium on the phase stabilization of $\gamma$-U, lattice parameter, microstructure and elemental composition were examined by X-ray diffraction (XRD), scanning electron microscopy (SEM) and energy dispersive spectroscope (EDS) techniques. The alloys crystallized in a cubic symmetry composed by a $\gamma-\mathrm{U}(\mathrm{Zr}, \mathrm{Nb})$ matrix and $\beta-\mathrm{Zr}$ small precipitates, when the content of zirconium and niobium is up to $55 \mathrm{wt} . \%$. With further additions, e.g. $60 \mathrm{wt} . \%$, was observed a highly enriched macrosegregation of $\beta$-Zr. It was also observed that the cell size of the $\gamma-\mathrm{U}(\mathrm{Zr}, \mathrm{Nb})$ phase increase with the addition of $\mathrm{Zr}$ and $\mathrm{Nb}$. The lattice parameter curve behavior as a function of zirconium and niobium deviates from a linear behavior at around $\mathrm{x} \approx 50$ and $\mathrm{y} \approx 10 \mathrm{wt} . \%$.
\end{abstract}

Keywords: $U$-Zr-Nb, Uranium alloys, Microstructure, X-ray diffraction

\section{Introduction}

The $\gamma-\mathrm{U}(\mathrm{M})$ alloys - with $\mathrm{M}=\mathrm{Al}, \mathrm{Ti}, \mathrm{Zr}, \mathrm{Nb}$ and $\mathrm{Mo}$ - are potential metallic fuels candidates for fast reactors, due to their superior properties compared to unalloyed uranium and other alloys ${ }^{1}$, once they are more resistant to corrosion and thermal cycling. Elements such as $\mathrm{Mo}, \mathrm{Nb}, \mathrm{Ti}$, and $\mathrm{Zr}$ are often used as substituting materials for stabilize the $\gamma$-U phase at low temperatures. The $\gamma$ phase of pure uranium cannot be retained in a metastable condition at low temperatures i.e., at temperatures at which $\alpha$ is the equilibrium phase. Moreover, these elements have low thermal-neutron cross section and high solubility in the $\gamma$-U phase. The $\mathrm{Zr}$ is preferable because it is a stronger $\gamma$-stabilizer, as well as Mo. In the other hand, the addition of $\mathrm{Nb}$ to the $\gamma$-U can significantly increases the corrosion resistance in the $\gamma$-quenched condition. Hence, it is a logical step to add $\mathrm{Nb}$ and $\mathrm{Zr}$ together into $\gamma$-U to form ternary $\gamma$-U-Zr-Nb alloys ${ }^{1-3}$.

The $\gamma$-U(M) alloys has been produced by powder metallurgy, induction, and arc melting routes ${ }^{3-5}$. There are some reports in literature on $\mathrm{U}-\mathrm{Zr}-\mathrm{Nb}$ ternary alloys, performed near the $\mathrm{U}$ rich corner ${ }^{2,3,6,7}$, but not many around the $\mathrm{Zr}$ rich corner $^{8,9}$. In this sense, the aim of this study is to investigate the formability of $\mathrm{U}-\mathrm{Zr}-\mathrm{Nb}$ zirconium-rich alloys with cubic structure, varying the uranium and niobium concentration produced by arc melt technique. Besides that, we tried to extend the limited information regarding the microstructural characteristics of U-Zr-Nb alloys monolithic nuclear fuels with higher zirconium concentration.

*e-mail: ailtonsfn@hotmail.com.
For these investigations, an elemental examination was performed by dispersive energy spectroscopy (EDS), while the structure and microstructure analyzes were conducted by $\mathrm{X}$-ray diffraction (XRD) and scanning electron microscopy (SEM) technique. The results here reported are imperative for metallic fuel design.

\section{Experimental Details}

Uranium alloys with the compositions U-32Zr- $6 \mathrm{Nb}$, U-42Zr-8Nb, U-46Zr-9Nb and U-50Zr-10Nb, in weight percent wt.\%, were prepared by arc-melting technique in a plasma furnace. We used a non-consumable tungsten electrode with a copper crucible under argon atmosphere. To maximize homogenizations the samples were re-melted at least three times. After fusion, the alloys were suitably sectioned and mechanically polished, firstly with sandpapers and further with diamond paste. After this metallographic preparation, the samples were immediately analyzed by XRD and SEM/ EDS techniques.

The X-ray diffractometry was conducted in the BraggBrentano geometry, using the $\mathrm{CuK}_{\alpha}$ radiation (Shimatzu $\mathrm{XRD}-6000, \mathrm{CuK}_{\alpha}, 40 \mathrm{kV}$ ) at $2 \theta$ range from $20^{\circ}$ to $120^{\circ}$ and a scan rate of $0.02 \% \mathrm{~min}$. All XRD patterns were refined by the Rietveld analysis method, applying the GSAS software ${ }^{10}$. To determine what phases are present, the ICSD database crystallography ${ }^{11}$ was used and the codes 44392 for $\gamma$-U and 52544 for $\beta-\mathrm{Zr}$ were considered to fit the whole pattern. For microstructure analyses, scanning electron microscope (SEM) along with quantitative compositional microanalysis made 
by means of energy dispersive spectroscopy (EDS) were used (Philips XL30 SEM combined with a EDAX PV9800).

\section{Results and Discussion}

\subsection{X-ray diffraction}

Figure 1 shows the XRD patterns of the as-cast alloys. Comparing them with the reference patterns (pointed out in the methodology section) we see that all the profiles correspond to a $\gamma-\mathrm{U}-$-like structure ${ }^{2}$. It is also observed that the peak positions are shifted towards lower $2 \theta$ values with increasing concentration of the alloying elements, as shown for the (110) plane in the inset. Thus, one can suggest that for all samples substitutionals solid solutions were formed with $\mathrm{Zr}$ and $\mathrm{Nb}$ atoms replacing $\mathrm{U}$ in the $\gamma$ structure, as also was identified by Ewh et al. ${ }^{2}$ in the ternary U-10Nb-4Zr alloy. A close inspection of the backgrounds in the diffractograms shows that there is no significant evidence of $\gamma$-phase decomposition, either of a $\alpha$-phase or $\delta$-phase. Due to the peak overlapping of the $\gamma-\mathrm{U}(\mathrm{Zr}, \mathrm{Nb})$ phase with the $\beta-\mathrm{Zr}$ phase, because they have the same spatial group (Im-3m), the presence of $\beta-Z r$ phase was only confirmed after SEM and EDS analyzes, as will be seen later in the micrographs. Therefore, the XRD patterns were refined considering both, $\gamma-\mathrm{U}(\mathrm{Zr}, \mathrm{Nb})$ and $\beta-\mathrm{Zr}$, as present phases. Aiming to illustrate the quality of the refinements, figure 2 shows the total calculated pattern (red line), superimposed to the experimental profile (black open circle), and the patterns calculated for $\gamma-\mathrm{U}(\mathrm{Zr}, \mathrm{Nb})$ (green line) and $\beta-\mathrm{Zr}$ (blue line) phases present in the $\mathrm{U}-32 \mathrm{Zr}-6 \mathrm{Nb}$ alloy. An excellent agreement between total calculated and experimental pattern can be observed.

Table I summarizes some relevant refined parameters, as obtained by Rietveld analysis. The lattice parameters calculated for the $\gamma-\mathrm{U}(\mathrm{Zr}, \mathrm{Nb})$ phase were plotted as function of $\mathrm{Zr}$ and $\mathrm{Nb}$ concentrations as shown in figure 3 . It is observed an increasing in the lattice parameters of the $\gamma-\mathrm{U}(\mathrm{Zr}, \mathrm{Nb})$ phase with the increasing concentration of zirconium and niobium. This is corroborated by the observed shift toward lowers $2 \theta$ angles, as already revealed by the inset in figure 1 . These results show that the increasing of the alloying elements concentration is responsible for the increasing in the lattices

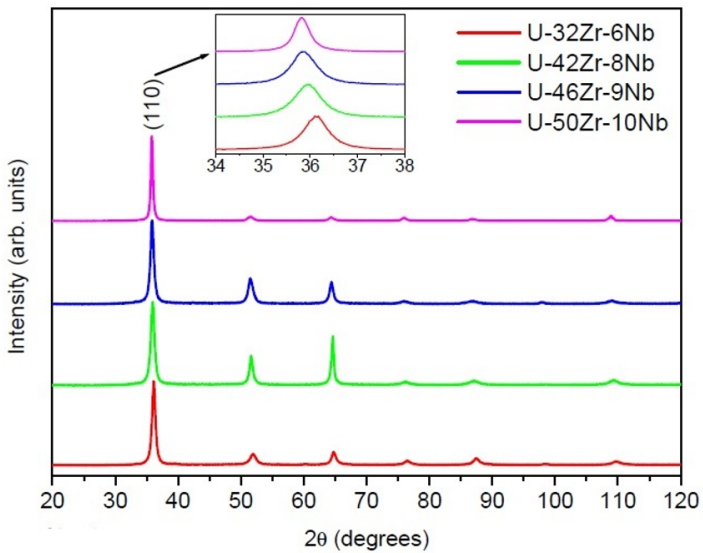

Figure 1. X-ray diffraction patterns for the U-Zr-Nb alloys.

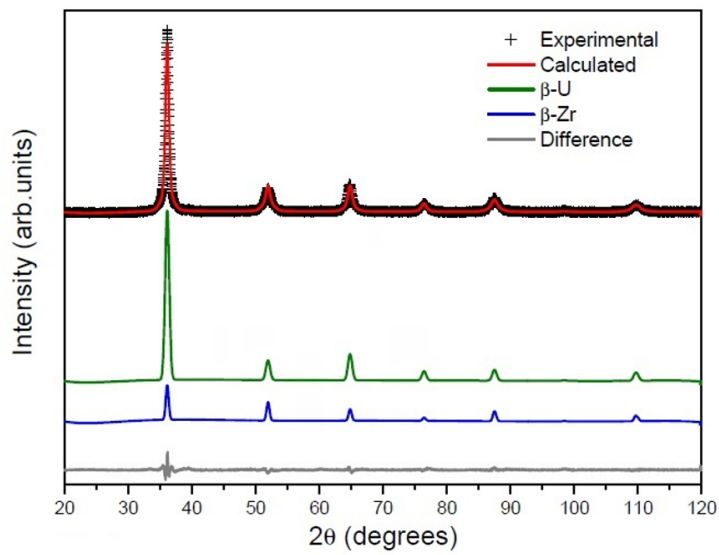

Figure 2. Refined diffraction pattern for the U-32Zr-6 Nb alloy.

parameters. Which is explained based on the fact that the atomic radius of the alloying elements dissolved in the $\gamma$-U phase are greater than the atomic radius of the $\mathrm{U}$, i.e., the atomic radius for $\mathrm{Zr}, \mathrm{Nb}$ and $\mathrm{U}$ are $1.60 \AA, 1.43 \AA$ and $1.39 \AA$, respectively ${ }^{12}$. Moreover, this result shows that the increasing of the lattice parameter with $\mathrm{Zr}$ and $\mathrm{Nb}$ content up to $55 \mathrm{wt} . \%$, obeys the Vegard's law, which states that the lattice parameters of a solid solution must change linearly with solute content ${ }^{13-15}$. For further additions, e.g. 60 wt.\%, a slightly deviation from linear dependence of the lattice parameters was observed, suggesting that solubility limit

Table 1. Summary of some relevant refined parameters, as obtained by Rietveld analysis.

\begin{tabular}{ccccc}
\hline \multicolumn{5}{c}{ Alloy } \\
\hline Parâmetro & U-32Zr-6Nb & U-42Zr-8Nb & U-46Zr-9Nb & U-50Zr-10Nb \\
\hline $\mathrm{R}_{\text {wp }}(\%)$ & 11.89 & 13.59 & 12.37 & 11.17 \\
$\gamma-\mathrm{U}$ & & & 3.5455 \\
$\mathrm{a}(\AA)$ & 3.5297 & 3.5400 & 51.513 & 3.5365 \\
Amount (wt.\%) & 58.247 & 40.997 & & 35.464 \\
$\beta-Z \mathrm{r}$ & & & 3.5475 & 3.5420 \\
$\mathrm{a}(\AA)$ & 3.5292 & 3.5300 & 48.487 & 64.536 \\
Amount (wt.\%) & 41.753 & 59.003 & & \\
\hline
\end{tabular}




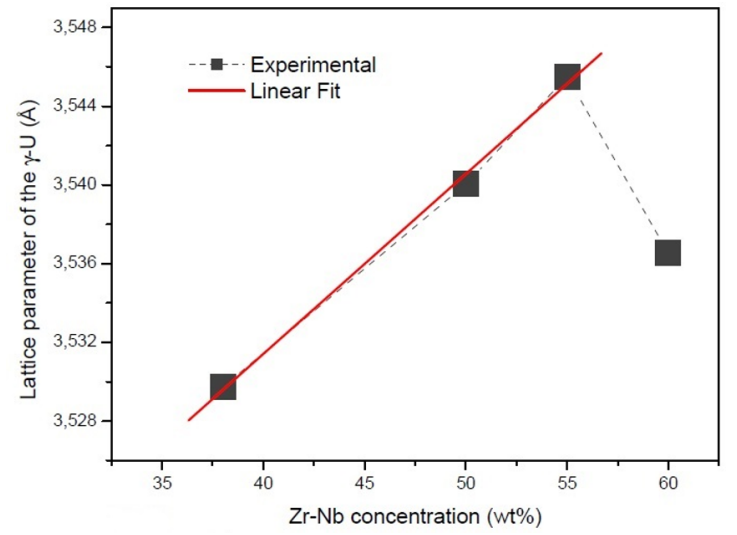

Figure 3. Lattice parameter for the $\gamma-\mathrm{U}(\mathrm{Zr}, \mathrm{Nb})$ phase versus the $\mathrm{Zr}$ and $\mathrm{Nb}$ concentration.

of $\mathrm{Zr}$ and $\mathrm{Nb}$ in the $\gamma-\mathrm{U}$ has been reached. It is interesting to note, that an increasing of the lattice parameter for the $\gamma$-U phase as a function of increasing $\mathrm{Zr}$ concentration was also observed by Bozzolo et al. ${ }^{15}$ in their theoretical studies in U-Zr solid solutions with concentrations ranging from 5 up to $70 \mathrm{wt} . \% \mathrm{Zr}$. As can seen in Table, the relative weight fraction of the $\beta-\mathrm{Zr}$ phase is greater for last sample, which is in qualitative agreement with the microstructure (as will be seen later).

\subsection{Scanning electron microscopy and energy dispersive spectroscopy}

Figures 4 to 7 show SEM images obtained for some representative samples. To measure homogeneity, the samples were scanned with the help of an EDS at different locations and a representative EDS spectrum is shown in the Figures (Figs. 4b, 4c to 7b, 7c). The micrographs of the U-32Zr-6Nb (Fig. 4a), U-42Zr-8Nb (Fig. 5a) and U-46Zr-9Nb (Fig. 6a) alloys are very similar and clearly reveal the presence of two phases, i.e., the matrix and small precipitates. There are regions of a darker contrast, as compared to the precipitates, and we believe that these regions are oxide inclusions. The absence of this oxide in the X-ray diffractograms can be explainable based on its low volumetric amount that is beyond the detection limit of the XRD technique. A SEM micrograph very similar to the ones obtained in present study, was reported for $\mathrm{U}-10 \mathrm{Nb}-4 \mathrm{Zr}$ alloy in Ref. ${ }^{1}$, in which the only phase identified by XRD was the $\gamma$-U phase.

In order to separate the $\beta-\mathrm{Zr}$ precipitates and improve your visualization from the surrounding $\gamma-\mathrm{U}(\mathrm{Zr}, \mathrm{Nb})$ matrix at micrograph, the image captured by SEM of the U-46Zr-9Nb alloy (Fig. 6a) was analyzed qualitatively with the open-source image processing program ImageJ (Image Processing and Analysis in Java) software ${ }^{16}$. For this, brightness and contrast thresholds were adjusted. Once the precipitate exhibited a clear, visible contrast to the background, the image was altered using the binary function (Fig. 8). This technique illuminated the $\mathrm{Zr}$-rich precipitates (dark), separating them from the surrounding $\gamma-\mathrm{U}(\mathrm{Zr}, \mathrm{Nb})$ matrix (white).

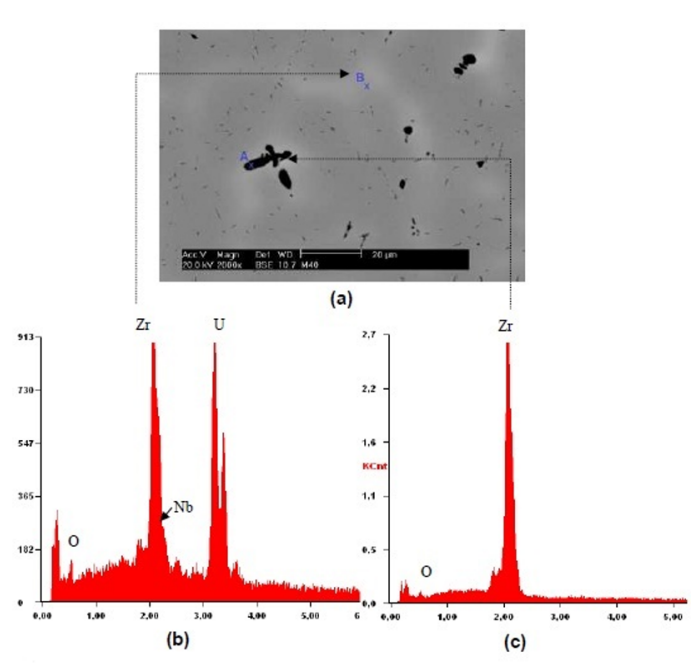

Figure 4. SEM micrograph of U-32Zr-6Nb alloy with EDS spectrum.
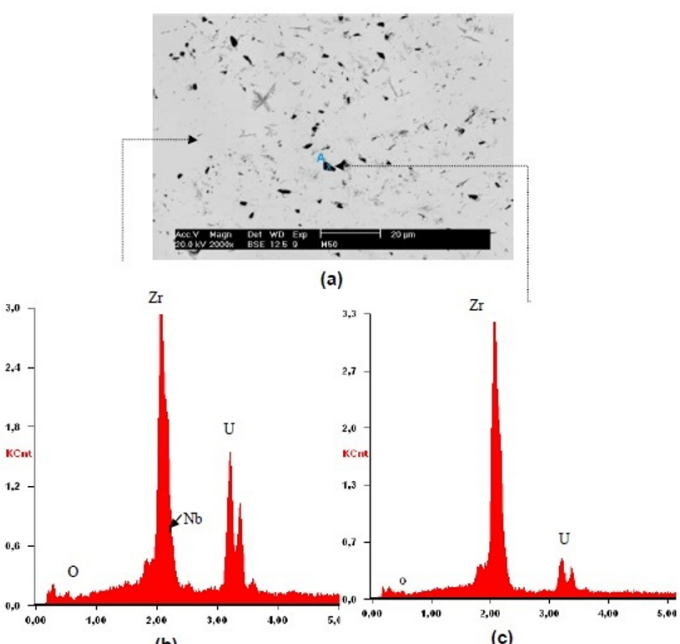

(b)

(c)

Figure 5. SEM micrograph of U-42Zr-8Nb alloy with EDS spectrum.

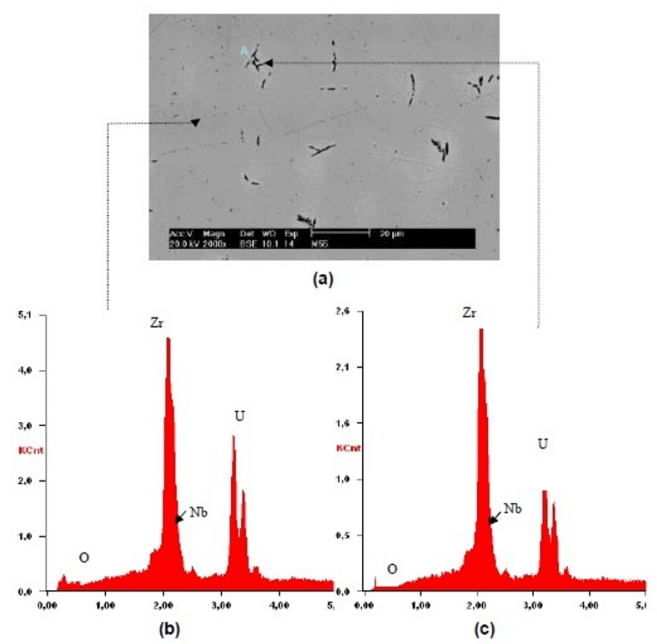

Figure 6. SEM micrograph of U-46Zr-9Nb alloy with EDS spectrum. 


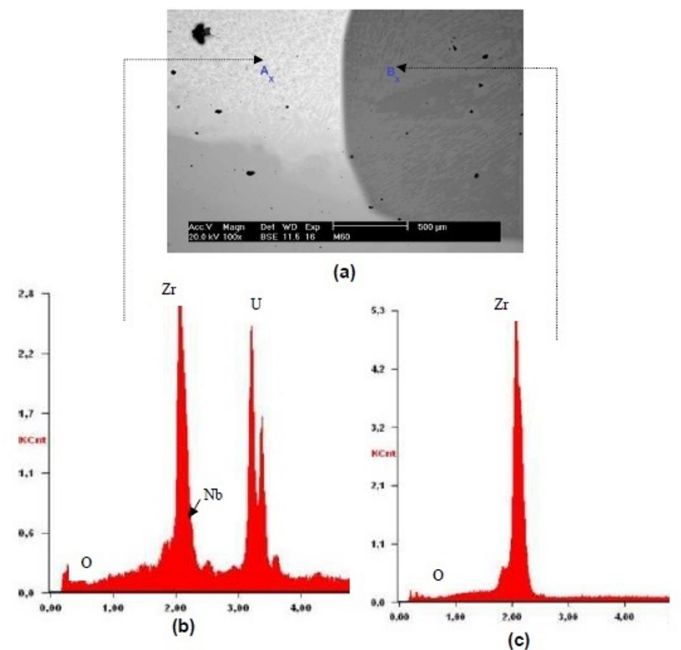

Figure 7. SEM micrograph of U-50Zr-10Nb alloy with EDS spectrum.

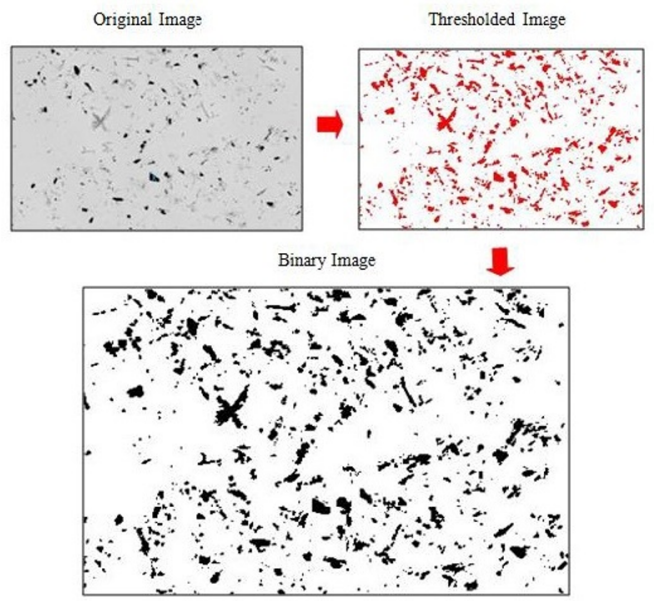

Figure 8. Original, Thresholded, and Binary SEM images of the $\mathrm{U}-46 \mathrm{Zr}-9 \mathrm{Nb}$ alloy in ImageJ.

From the EDS results, it can be observed that the matrix contains all alloys elements and that there is a difference in the $\mathrm{Zr}$ concentration between the matrix and precipitates. The shape of EDS spectrum changes significantly from the matrix to the precipitates: the uranium and niobium peaks have not been detected in EDS spectrum to the precipitates, while the zirconium peaks is always present. EDS spectrum reveals that the compositions of the precipitates are $\mathrm{Zr}$-rich, as shown in Figures $4 \mathrm{c}$ to $6 \mathrm{c}$. The elemental analyses is compatible to the $\gamma-\mathrm{U}(\mathrm{Zr}, \mathrm{Nb})$ phase (matrix), while the $\mathrm{Zr}$-rich regions may be attributed to the precipitates crystallized in the $\beta-Z r$ phase. These results clearly indicates that only $\gamma-\mathrm{U}(\mathrm{Zr}, \mathrm{Nb})$ and $\beta-\mathrm{Zr}$ phase formation occurs and the observed phases from XRD and SEM images, confirm this observation. It is interesting to note that $\beta-\mathrm{Zr}$ precipitates formed in the $\mathrm{U}-\mathrm{Zr}-\mathrm{Nb}$ alloys, were also observed in the studies of Lee et al..$^{5}$ on extruded metallic alloys consisting of U-80at.\%Zr.
On the other hand, in the SEM micrograph of the U-50Zr-10Nb alloy (Fig. 7a), was observed a light gray region and a large dark gray region with the size in the order of millimeters. According to the EDS result, the former contains all alloying elements (Fig. 7b) and the later is highly enriched in zirconium (Fig. 7c). This macro segregation can be caused by the phase separation of $\mathrm{Zr}$, again crystallized with the $\beta-Z r$ structure, during the solidification of the alloy from the liquid phase. From this result, we suggest that the solubility limit of $\mathrm{Zr}$ in $\gamma$-U is lower than $50 \mathrm{wt} . \%$, as indicated by the XRD analysis, where a deviation from the linear dependence of the lattice parameter as function of the $\mathrm{Zr}$ and $\mathrm{Nb}$ content was observed.

\section{Conclusions}

Uranium alloys with concentrations ranging from 32 to $46 \mathrm{wt} . \% \mathrm{Zr}$ and from 6 to $9 \mathrm{wt} . \% \mathrm{Nb}$ were prepared by arcmelting technique in a plasma furnace. The XRD analysis and SEM micrographs showed the effectiveness of the $\mathrm{Zr}$ and $\mathrm{Nb}$ in the stabilizing of the $\gamma-\mathrm{U}(\mathrm{Zr}, \mathrm{Nb})$ phase. The results also showed that the alloys are composed of a $\gamma-\mathrm{U}(\mathrm{Zr}, \mathrm{Nb})$ matrix and of $\beta-Z r$ small precipitates. However, with further additions of $\mathrm{Zr}$ and $\mathrm{Nb}$ it was observed a macrosegregations with sizes in the order of millimeters, highly enriched in $\beta-Z r$. Moreover, the results showed that the lattice parameters of $\gamma-\mathrm{U}(\mathrm{Zr}, \mathrm{Nb})$ alloys are increasing linearly with the $\mathrm{Zr}$ and $\mathrm{Nb}$ content up to $55 \mathrm{wt} . \%$, following the Vegard's law. With further additions, e.g. 60 wt.\%, deviations from Vegard's law were observed, showing that solubility limit of $\mathrm{Zr}$ and $\mathrm{Nb}$ in $\gamma$-U it was reached.

\section{Acknowledgements}

The authors would like to thank to the Brazilian agencies CAPES and to Nuclear Materials Laboratory (CTMSPBRAZIL), for financial and experimental support.

\section{References}

1. Kim-Ngan NTH, Tkach I, Mašková S, Havela L, Warren A, Scott T. Cubic $\gamma$-phase U-Mo alloys synthesized by splat-cooling. Advances in Natural Sciences: Nanoscience and Nanotechnology 2013;4(3):035006.

2. Ewh A, Perez E, Keiser DD Jr., Sohn YH. Microstructural Characterization of U-Nb-Zr, U-Mo-Nb, and U-Mo-Ti Alloys via Electron Microscopy. Journal of Phase Equilibria and Diffusion. 2010;31(3):216-222.

3. Ghoshal K, Kaity S, Mishra S, Kumar A. Microstructural investigation of uranium rich $\mathrm{U}-\mathrm{Zr}-\mathrm{Nb}$ ternary alloy system. Journal of Nuclear Materials. 2014;446(1-3):217-223.

4. Sinha VP, Prasad GJ, Hegde PV, Keswani R, Basak CB, Pal S, et al. Development, preparation and characterization of uranium molybdenum alloys for dispersion fuel application. Journal of Alloys and Compounds. 2009;473(1-2):238-244. 
5. Lee CT, Kim H, Kim TK, Lee CB. Diffusion behavior in an interface between U-10Zr alloy and HT-9 steel. Journal of Nuclear Materials. 2009;395(1-3):140-144.

6. Park JM, Kim KH, Sohn DS, Kim CK, Hofman GL. Characterization of U-Nb-Zr dispersion fuel prepared by centrifugal atomization process. Journal of Nuclear Materials. 1999;265(1-2):38-43.

7. Meyer MK, Hofman GL, Wiencek TC, Hayes SL, Snelgrove JL. Irradiation behavior of U-Nb-Zr alloy dispersed in aluminum. Journal of Nuclear Materials. 2001;299(2):175-179.

8. Lee CT, Park JH, Kim TK, Lee UJ, Lee BS, Sohn DS. Thermal stability of co-extruded U-Zr/Zr-Nb alloys. Journal of Nuclear Materials. 2008;373(1-3):275-279.

9. Komar Varela CL, Gribaudo LM, González RO, Aricó SF. Transformation behavior of the $\gamma \mathrm{U}(\mathrm{Zr}, \mathrm{Nb})$ phase under continuous cooling conditions. Journal of Nuclear Materials. 2014;453(1-3):124-130.

10. Larson AC, Von Dreele RB. General Structure Analysis System (GSAS). Los Alamos National Laboratory Report LAUR. 2000;86-748.
11. Gmelin - Institute fur Anorganische Chemie und Fachinformationszentrum. Inorganic Crystal Structure Database (ICSD). Gmelin. Berlin: FIZ Karlsruhe; 1995.

12. McCormick S, Morefield G, McCormick M, McCormick A. TAPP - A Database of Thermochemical and Physical Properties. Hamilton: E.S. Microware; 1991.

13. Sidot E, Kahn-Harari A, Cesari E, Robbiola L. The lattice parameter of a-bronzes as a function of solute content: application to archaeological materials. Materials Science and Engineering. A. 2005;393(1-2):147-156.

14. Barbu A, Bratu I, Borodi G. Photoacoustic and X-ray investigations of $\mathrm{Ni}_{100-\mathrm{x}} \mathrm{Cu}_{\mathrm{x}}$ alloys. Materials Letters. 1995;24(4):231-233.

15. Bozzolo G, Mosca HO, Yacout AM, Hofman GL, Kim YS. Surface properties, thermal expansion, and segregation in the U-Zr solid solution. Computational Materials Science. 2010;50(2):447-453.

16. Schneider CA, Rasband WS, Eliceiri KW. NIH Image to ImageJ: 25 years of image analysis. Nature Methods. 2012;9:671-675. 